\title{
İki Boyutlu Silindirik Dağıtıcılı Sonik Kristal Yapılarının Akustik Lens Özelliklerinin Zaman Bölgesi Sonlu Fark Simülasyonları ile İncelenmesi
}

\begin{abstract}
Fotonik kristallerde gözlemlenen birçok dalga yayılım özellikleri sonraları sonik kristaller üzerinde gösterilmiştir. Sonik kristal yapılar negatif kırınım, düzlem lens, dalga kılavuzları gibi birçok akustik dalga uygulamasına imkân sağlayan akustik metamateriyaldir ve sonic kristal uygulamaları son yılarda yoğun bir şekilde çalışılmaktadır. Bu çalışmada iki boyutlu temel sonik kristal yapıları kısaca tanıtılmakta ve zaman bölgesi sonlu farklar (Finite Difference Time DomainFDTD) yöntemi simülasyon sonuçları ile sonik kristal yapılarda negatif kırınım özelliği ve dalga odaklama uygulamalarının bir incelemesini sunulmaktadır. Negatif kırınım ve buna bağlı olarak gerçekleşen akustik dalgaların odaklanmasını konu alan pek çok çalışma bulunmaktadır. Bu çalışma bu konuda yapılan önemli çalışmaları kısaca incelenmekte ve zaman bölgesi sonlu farklar yöntemi simülasyonları yardımı ile negatif kırınım ve bununla ilişkili akustik dalga odaklanma olaylarının zaman bölgesi simülasyon sonuçlarını sunmaktadır. Araştırma sonuçları zaman bölgesi sonlu farklar simülasyonlarının sonik kristal düzlem lens tasarımı çalışmalarında kullanılabileceğini göstermiş̧tir.
\end{abstract}

Keywords: Sonik kristaller, negatif kırınım, düz lens, zaman bölgesi sonlu farklar simülasyonu

\section{Investigation of Acoustic Lens Properties of Two-dimensional Cylindrical Scatterer Sonic Crystal Structures via Finite Difference Time Domain Simulations}

\begin{abstract}
Many wave propagation properties, which were observed in photonic crystals, have been demonstrated for sonic crystals, later. The sonic crystal structures are acoustic metamaterials that allow acoustic wave applications such as negative refraction, flat lens, wave guides, and their applications have been intensively studied in recent years. This study introduces fundamental twodimensional sonic crystal structures and presents an overview for the negative refraction properties and its wave focusing applications by using Finite Difference Time Domain (FDTD) simulation results. There are many studies that address negative refraction and its associated phenomenon acoustic wave focusing. This study briefly reviews some important studies related to this topic and presents timedomain simulation results in order to illustrate negative refraction and the related acoustic wave focusing phenomenon by means of FDTD simulations. Research findings indicates that FDTD simulations can be used for design tasks of sonic crystal flat lens.
\end{abstract}

Keywords: Sonic crystals, negative refraction, flat lens, FTDT simulation 


\section{GİRIŞ}

Akustik dalga yayılım ortamlarının periyodik olarak iletim özelliklerinin değiştirilmesi ile elde edilen heterojen dalga iletim ortamlarına sonik kristal yapılar adı verilmiştir (Miyashita and Inoue, 2001; Miyashita, 2005). Homojen dalga yayılma ortamının periyodik olarak ikincil bir ortam ile heterojen hale getirildiği kristal yapılarda, dalga yayılımının ilginç özellikler gösterdiği görülmüş ve yeni teknolojiler geliştirme potansiyeline sahip bu sahaya ilgi sürekli artmıştır (Sigalas and Garcia, 2000; Miyashita, 2005; Hirsekorn, 2006). Bu çalışmalar meyvelerini vermeye başlamış; negatif kırılma indisine sahip sol elli malzemeler (Metamalzemeler) geliştirilmiş ve bu malzemeler ile yüksek odaklama kabiliyetlerine sahip üstün lens, dalga kılavuzları, dalga frekansına bağlı olarak seçicilik gösterebilen dalga filtreleri yapılabilmiştir (Cervera et al., 2001; Chao-Hsien et al., 2004; Miyashita, 2005).

Elektromanyetik dalgalar için kullanılan kristal yapılara fotonik kristaller, akustik dalgalar için oluşturulan kristal yapılara sonik kristaller adı verilmiştir. Fotonik kristallerde keşfedilen birçok özellik (Veselago, 1968; Pendry, 2000; Ozbay, 2007) daha sonra sonik kristallerde gözlenmeye başlamıştır (Liu et al., 2019). Kristal örgü uygulamaları, elektromanyetik dalga ve akustik dalgalar ile sınırlı kalmamış, sismik dalgaların sismik kristal veya sismik metamaterial adı verilen periyodik olarak sismik dalga yayılım özelliğinin bozulması ile oluşturulan ortamların, frekans cevabında band boşlukları adı verilen frekans bölgelerinde sismik dalgaların zayıflatabileceğini öngören teorik çalışmalar yapılmış ve deneysel uygulamalar gösterilmiştir (Alagoz and Alagoz, 2011; Miniaci et al., 2016; Mu et al., 2020; Wang, 2020).

Literatürde, dalganın kristal yapı içinde yayıldığı ana ortama ev sahibi materyal (Host Material), periyodik olarak dizilen ve dalganın kırınım ve saçılımını sağlayan ikincil ortama dağıtıcı materyal ( Scattering Material) adı verilir. Kristali oluşturan periyodik dağıtıcı dizisi bir boyutta değişiyorsa bu örgü bir-boyutlu (1D) kristal yapı oluşturur. Örneğin arka arkaya dizilen paralel levha katmanları birboyutlu örgü oluşturur. Eğer dağıtıcı materyal iki-boyutta değişiyorsa; iki boyutlu bir (2D) kristal yapı oluşturur. Örneğin, dağıtıcı materyal silindirik formda ise bu silindirlerin bir düzlem boyunca belli periyodik dizilmesi ile iki-boyutlu kristal meydana getirir. Şekil 1'de iki boyutlu sonik kristal yapının bir çizimi görüşmektedir. Üç-boyutlu kristal, dağıtıcı materyalin üç boyutta değişkenlik göstermesi ile elde edilir. Örneğin küre ya da küp biçimli dağıtıcı materyallerin üç boyutlu bir hacim içine periyodik bir düzen içinde dizilmesi ile üç-boyutlu kristal elde edilir. Bu çalışmada, literatürde araştırmaların yoğunlaştığı iki-boyutlu sonik kristal temel yapılarını ve bu yapıların akustik dalga yayılım simülasyonları ile negatif kırılma ve akustik odaklanma özelliklerini inceleyeceğiz.

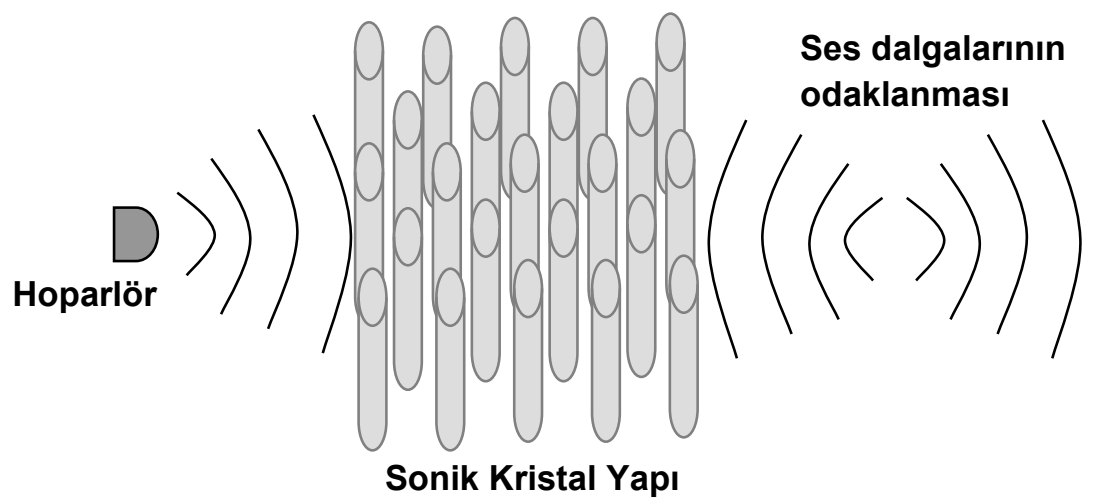

Şekil 1. İki boyutlu sonik kristal yapı ile ses dalgasının odaklanması olayı 


\section{2 İki Boyutlu Sonik Kristal Yapıları ve Negatif Kırınım}

Kristali oluşturan periyodik yapı primitif hücre adı verilen temel bir yapının kendini tekrarlaması ile elde edilir. Kristal yapılar, kendini oluşturan temel yapının geometrisi ile farklılaşırlar. İki-boyutlu kristaller içinde kendini tekrarlayan bu temel birim, dağıtıcı materyallerin yerleşim geometrisine bağlı olarak farlı örgü geometrileri oluşur. İki boyutlu kristal yapılar için başlıca örgü geometrileri Şekil 2 'de gösterilmiştir. Bu kristal yapılarda için iki önemli parametre söz konusudur. Birincisi, kafes sabiti adı verilen iki dağıtıcı ortam merkezleri arasındaki uzaklıktır ve genellikle $a$ ile gösterilir. Diğeri ise dağıtıcı yarıçapıdır ki; bu parametre çoğunlukla $r$ ile gösterilirler.
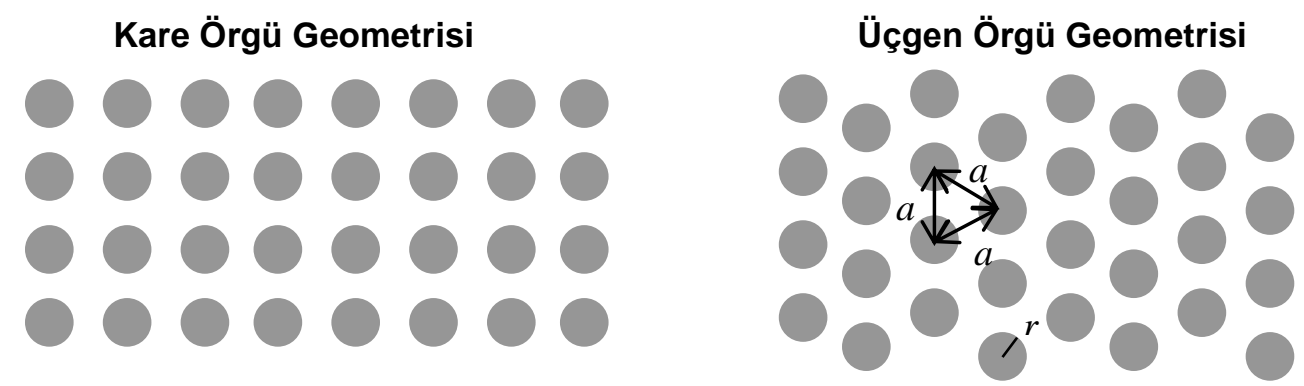

Şekil 2. Kare örgü ve üçgen örgü geometrili iki-boyutlu kristal yapılar. Gri yuvarlaklar dağıtıcı materyali, aralarındaki beyaz boşluklar ev sahibi materyali temsil etmektedir

Şekil 1'de iki-boyutlu sonik kristallerin odaklama özelliklerinin incelenebileceği düzenek temsili olarak gösterilmişti. Burada, hava ev-sahibi materyaldir. Diğer bir ifade ile ses dalgalarının yayılımını sağlayan ortamdır. Silindir çubuklardan oluşan diziler ise dağıtıcı materyallerdir. Sonik kristal üretimi için bu katı çubuklar alüminyum veya plastik gibi katı materyallerden üretilebilmektedir (MartinezSala et al., 1995; Miyashita and Inoue, 2001; Alagoz, 2011). Havaya göre yüksek yansıtma katsayısına sahip bu katı dağıtıcılar, ses dalgalarının kristal içinde saçılmasına ve dağıtıcı dizilerinin örgü geometrisine bağlı olarak modülasyona uğramalarına yol açarlar. Böylece, sonik kristal yapının frekans cevabında (Bant yapısında), dalga iletiminin sağlandığı iletim bantları ile dalga iletiminin zayıfladığı bant boşlukları gözlemlenir. Dolayısı ile sonik kristal yapının, iletim bandına karşılık gelen frekanslardaki dalgaları iletir ve bu frekanslarda dalga k1lavuzu veya dalga odaklama uygulamaları gerçekleştirilebilir. Bant boşluklarına karşılık gelen frekansda ise dalgaları sönümleyen (Zayıflatan) bir zayıflatıcı veya sönümleyiciye dönüşür ve dalga izolasyonu uygulamaları bu frekans bölgelerinde sağlanır. Yapılan deneysel ve teorik çalışmalarda, fotonik ve akustik kristallerin, ikinci iletim bantlarına karşılık gelen frekanslardaki dalgalar için negatif kırılma indisine sahip olduğunu görülmüştür (Foteinopoulou et al., 2003; Houck et al., 2003; Zhang and Liu, 2004; Qiu et al., 2005; Feng et al., 2005; Alagoz et al., 2009; Alagoz, 2011). Şekil 3'de kristal yapılar içinde negatif ve pozitif kırılma olayları temsili olarak gösterilmiştir. İkinci iletim bandı frekans bölgesi için negatif kırılma sağlayan bu kristaller, üstün odaklama kabiliyeti sağlayan üstün lenslerin geliştirilmesine imkân sağlamıştır (Qiu et al., 2005; Alagoz et al., 2009; Alagoz, 2011; Zhu et al., 2011; Liu, 2019). 


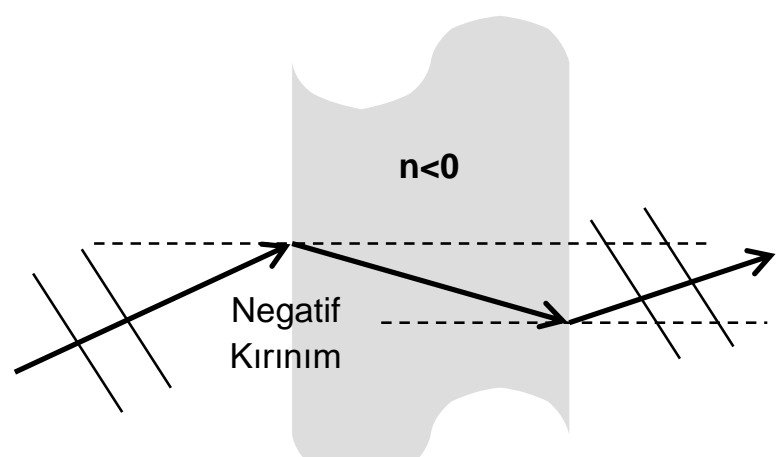

(a)

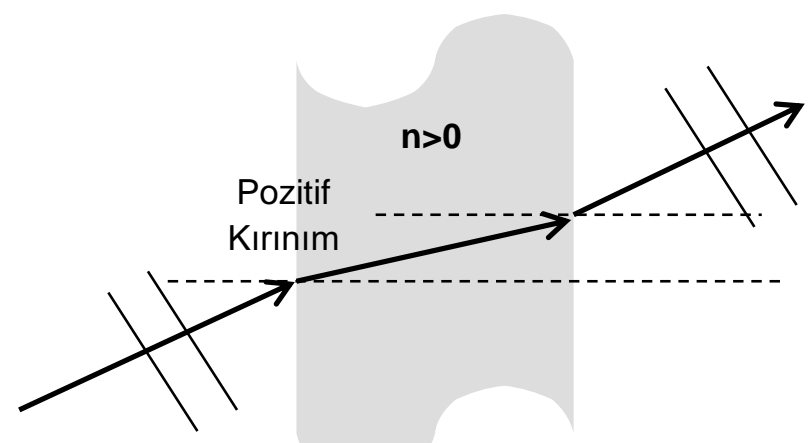

(b)

3 Şekil 3. (a) Negatif kırınım sonucu düzlem dalganın hareket doğrultusunda meydana gelen değişimler.

4 (b) Pozitif kırınım sonucu düzlem dalganın hareket doğrultusunda meydana gelen değişimler.

\section{BULGULAR VE TARTIŞMA}

\section{Zaman Bölgesi Sonlu Farklar Simülasyonları ile Sonik Kristallerde Negatif Kırınım Olayının} İncelenmesi

Sonik kristal yapıların ev-sahibi materyali, ses taşıma kabiliyetine sahip olmalıdır. Ev sahibi materyal olarak yaygın olarak hava kullanılır, ancak sıvılar da kullanılabilir. Dağıtıcı materyal, evsahibi materyale göre yüksek yansıma katsayısına sahip olmalıdır. Bu nedenle, katı malzemeler (alüminyum, çelik, plastik, ahşap, cam ..vb) diğer bir ifade ile yüksek yoğunluk ve bulk modülü gösterebilen materyaller tercih edilmelidir. İlk sonik kristal olarak heykeltraş Eusebrio Sempere'nın çelik çubukları paralel olarak dizerek gerçekleştirdiği eseri gösterilir. Her ne kadar sanatçı, eserini sanatsal bir kaygı ile üretse de Meseguer ve ekibi bu eserin $1.67 \mathrm{KHz}$ frekansındaki ses dalgalarını ciddi ölçüde zayıflattığını tespit etmişler ve eserin bu frekanslarda bir bant boşluğuna sahip iki-boyutlu bir sonik kristal yapı oluşturduğunu göstermişlerdir (Martinez-Sala et al., 1995). Daha sonraları zaman bölgesinde sonlu farklar simülasyonları ile yapılan akustik dalga incelemelerinde, ses dalgalarının negatif kırınımı ve odaklanması gibi etkiler gözlemlenmiştir (Cervera et al., 2001; Chao-Hsien et al., 2004; Qiu et al., 2005; Alagoz et al., 2009). 

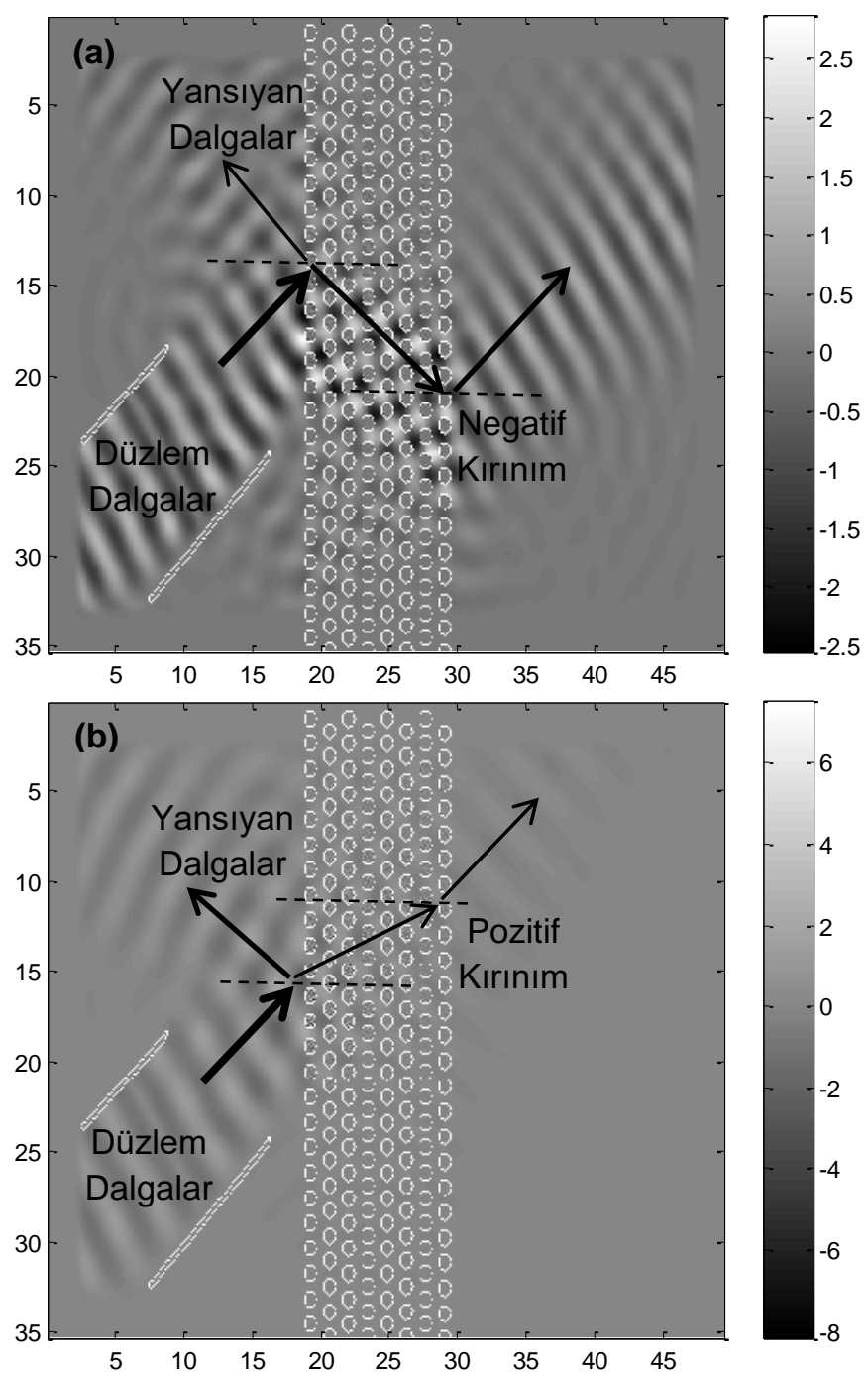

Şekil 4. (a) Sonik kristal yapıda elde edilen negatif kırınım ( $f=14000 \mathrm{~Hz}$ ), (b) Sonik kristal yapıda elde edilen pozitif kırınım ( $f=11000 \mathrm{~Hz}$ )

Üçgen örgü geometriye sahip iki-boyutlu sonik kristal yapıların simülasyonları zaman bölgesinde sonlu farklar yöntemi ile bilgisayar ortamında gerçekleştirilmiştir (Miyashita, 2005; Alagoz, 2012). Düzlem dalgaların sonik kristal yapı tarafından negatif ve pozitif kırınıma uğratılmaları Şekil 4'de sunulan simülasyon sonucunda gösterilmiştir. Şekil 4(a)'da görülen simülasyon sonucunda, sonik kristal yapının negatif kırılma indisine $(n<0)$ sahip olduğu belirgin bir şekilde görülmektedir. Düzlem dalganın önemli bir kısmı sonik kristal yapı içinde negatif kırınıma maruz kalırken, bir kısmı da sonik kristal yapıya giremeden yansımaya maruz kalmıştır. $\mathrm{Bu}$ durum, efektif negatif kırılma indisine sahip sonik kristal yapının bir efektif empedansa ve yansıma katsayısına sahip olduğuna işaret eder. Şekil 4(b)'de ise dalga frekansı düşürülerek birinci iletim bandında elde edilen pozitif kırınım simülasyon sonuçları görülmektedir. $\mathrm{Bu}$ durum bize, kristal yapının göstereceği efektif kırılma indisinin değerinin, kristale gelen dalganın frekansına bağlı değiştiğini göstermektedir (Jia and Zhang, 2007). 


\section{Özelliklerinin İncelenmesi}

Kristal yapılarda iki farklı karaktere sahip odaklama türü gözlemlenebilmektedir. Bunlardan birincisi, sonik kristal yapıların pozitif kırılma indisi gösterdiği frekanslarda gözlenir ve dışbükey şekle sahip sonik kristaller ile ses dalgalarının odaklanması sağlanır. Bu odaklanma türü, ışı̆̆ın ince kenar merceklerde kırılmasına benzer bir mekanizma ile ses dalgalarını odak noktasına toplar. Burada odaklamayı sağlayan mekanizma, akustik dalgaların kristal yapı içinde dış ortama nazaran daha yavaş yayılmasıdır. Bu hız farkı, kristal yapıya verilecek uygun bir şekil ile dalga zarfının odaklanmaya uygun olarak bükülmesini sağlar. Dalga yayılım hız farkına dayalı odaklama yöntemi, dışbükey lens yapısı ile sağlanabilmesi yanında sonik kristal içinde dalga iletim hızlarının farklılaştırıldığı gradyan indeksli sonik kristal yapılar ile de sağlanır (Climente et al., 2010). Şekil 5'de dalga yayılım hızı farkına dayalı odaklama mekanizmasından yararlanan mercek yapısı (dışbükey lens) yardımı ile düzlem dalganın odaklanmasını gösteren bir simülasyon sonucu gösterilmiştir.

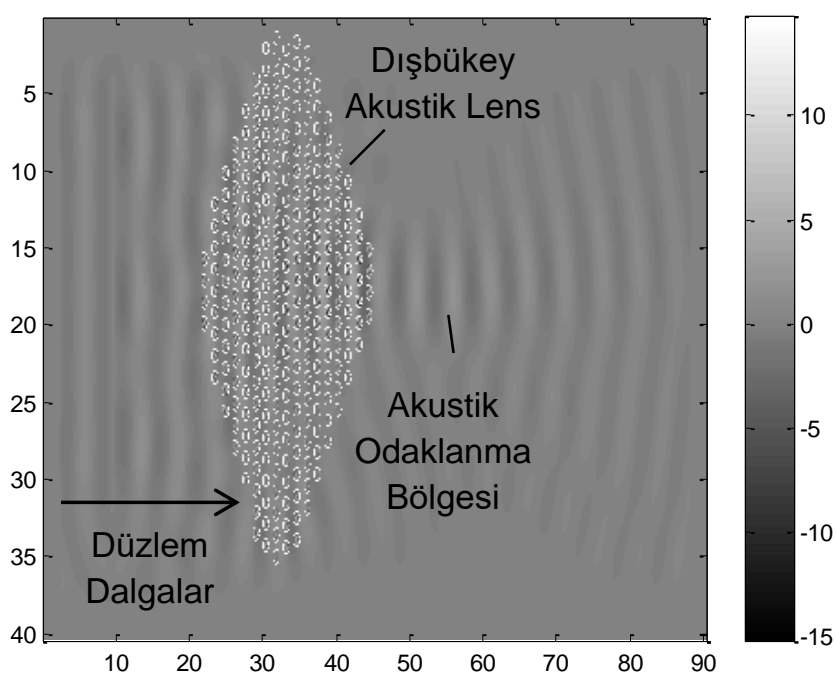

Şekil 5. Sonik kristal yapıların dışbükey kristal geometrisi ile sağladığı akustik odaklanma

Diğer bir odaklama türü ise negatif kırılma indisinin açığa çıktığı frekanslarda görülmektedir. Üstün lens olarak nitelendirilen bu özellik, kristal yapının negatif kırınım gösterdiği frekanslarda açı̆̆a çıkar ve dikdörtgen şekline sahip bir kristal yapı ile üstün akustik odaklama kabiliyeti sağlanabilir (Qiu et al., 2005; Alagoz, 2011; Liu et al., 2012; Liu et al., 2019). Bu lens yapisinın dalga boyu alt1 odaklama (Subwavelength focusing) (Liu et al., 2019) ve üstün çözünürlükte akustik görüntüleme (Liu et al., 2012; Liu et al., 2019) sağlayabileceği gösterilmiştir. Negatif kırılma koşullarında 1şın izleme tekniği kullanılırsa, dikdörtgen geometriye sahip kristal bloğun, Şekil 6'da temsili olarak gösterildiği gibi biri kristal içinde ve diğeri de kristalin arkasında olmak üzere iki odaklama noktası oluşturduğu görülür. Burada odaklanmaya neden olan mekanizma, pozitif kırınımın görüldüğü frekanslar ortaya çıkan ve kristal yapıya verilen şekil ile dalgaların yalım hızının değiştirilerek odaklanmasından farklı olarak, negatif kırınım olayının düz lenste doğal bir sonucudur (Qiu et al., 2005). Negatif kırınımın bir sonucu olarak sonik kristal düzlem lens yardımı ile noktasal kaynaktan çıkan küresel dalgaların kristalin diğer tarafında yüksek ayırıcılığa sahip (Subwavelength focusing) bir akustik odaklama sağlayabildiği gösterilmiştir (Liu et al., 2019). 


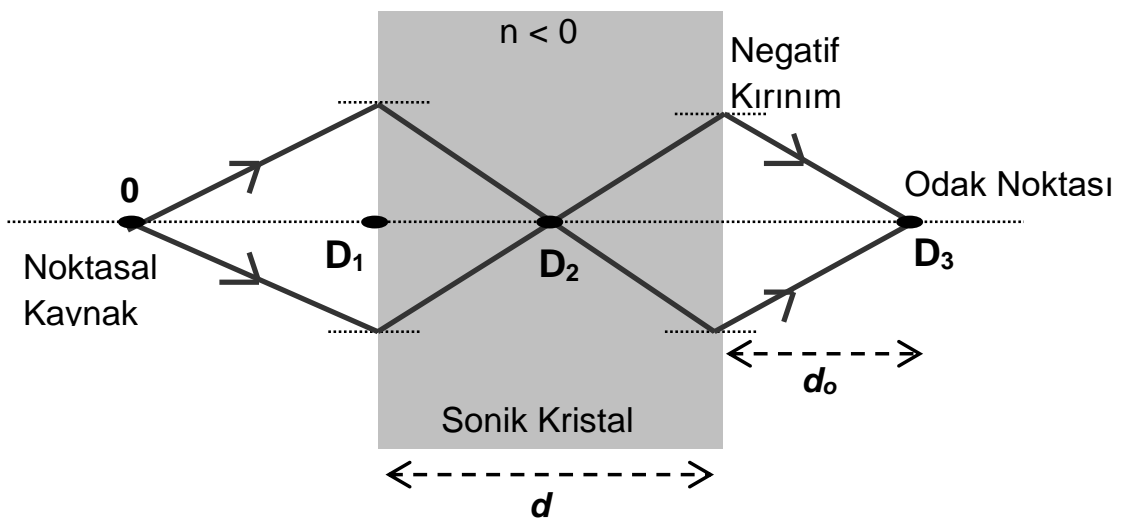

Şekil 6. Negatif kırılma durumunda $(n<0)$ düzlem lenslerde dalga odaklama (Qiu et al., 2005)

Şekil 7'de üçgen örgü geometrisine sahip iki-boyutlu sonik kristal yapı ile düzlem lens simülasyon sonucu sunulmuştur. Şekil 8 'de bu benzetimde elde edilen basınç şiddeti haritası görülmektedir.

İki boyulu ve dikdötgen biçimli sonik kristallerin negatif kırılma durumunda odak noktasının konumu, efektif kırılma indisi ( $n$ )'e bağlı olarak,

$$
D_{3}=(1+1 /|n|) \cdot d
$$

ile ifade edilmiştir (Qiu et al., 2005).

Üstün lens uygulamaları için, $n=-1$ durumu en iyi odaklama özellikleri ve en yüksek odaklama gücünün elde edildiği özel bir durumdur. Bu koşul altında, $D_{3}=2 d$ olarak ifade edilir. Şekil 6 göz önünde tutulursa, $D_{3}=d_{o}+d+D_{1}$ olduğu görülür. Bu iki ifade birlikte değerlendirilirse $d_{o}=d-D_{1}$ elde edilir. Buna göre, $n=-1$ durumunda, odak noktasının $\left(d_{o}\right)$ konumunun, kristal yapının genişliği ( $d$ ) ve dalga kaynağının kristale olan uzaklığı $\left(D_{1}\right)$ ile belirlendiği görülür.

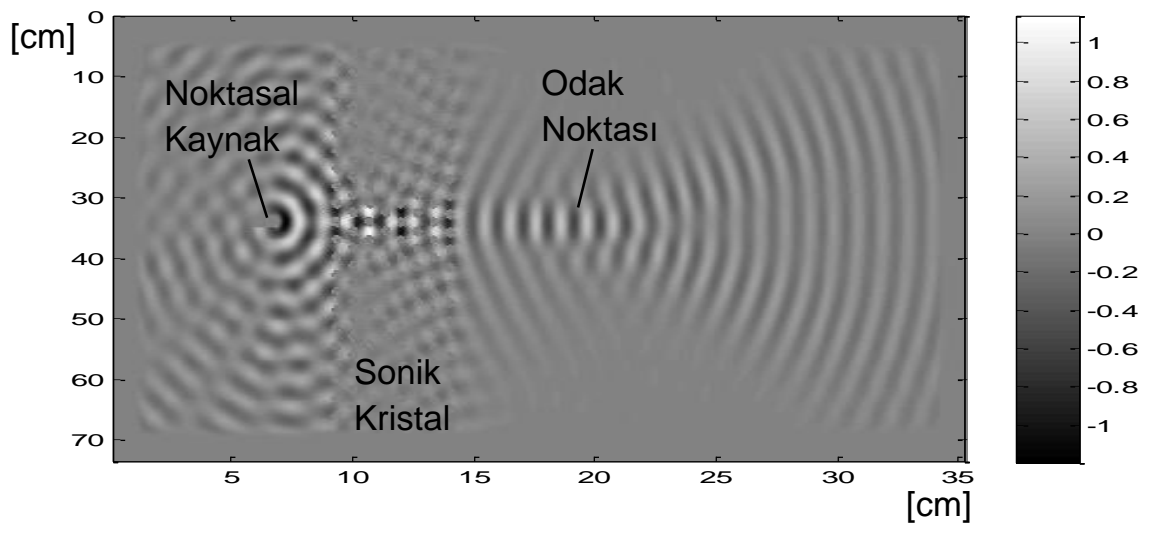




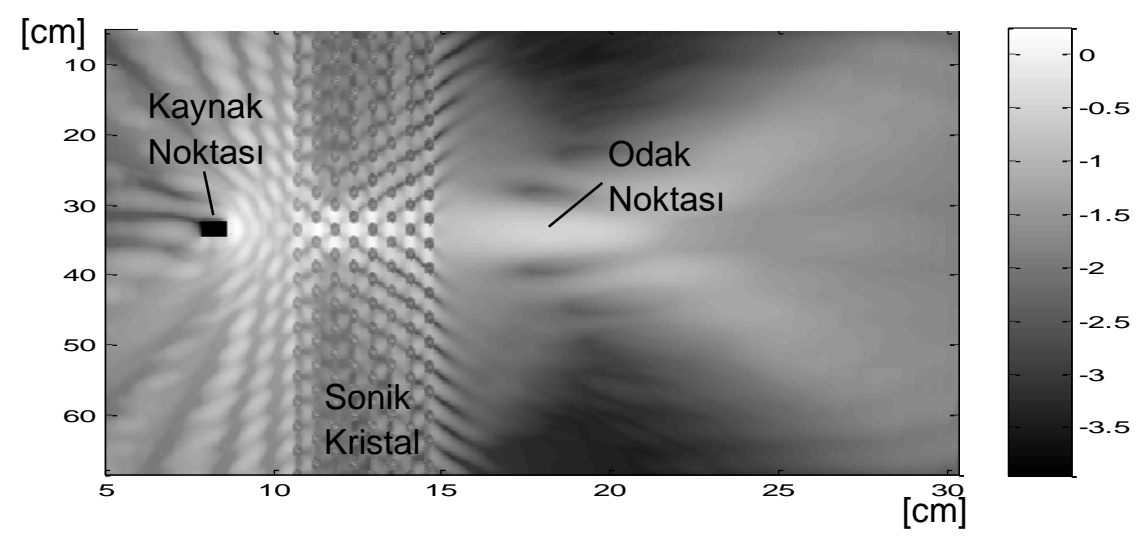

Şekil 8. Şekil 7'de görülen simülasyon sonucu için elde edilen maksimum basınç şiddeti haritası

Şekil 9,10 ve 11 'de $n \cong-1$ için, odak noktasının kristalden uzaklığının $d_{o}=d-D_{1}$ bağıntısına uygun olarak değişebildiği simülasyon sonuçlarında görülebilmiştir. Şekil 9 ve 10'da, öncelikle kaynak uzaklığı $D_{1}$ değiştirilerek odak noktasının konumunda oluşan değişimler incelenmiştir. Sonra, Şekil 11'de sonik kristal kalınlığ $d$ değiştirilerek odak noktasının konumundaki değişim gösterilmiştir. Şekil 9, 10 ve 11'de odak uzaklığının $d_{o}=d-D_{1}$ formülüne uygun değiştiği ve $n=-1$ durumunda akustik kaynağın kristale olan uzaklığı ile odak uzaklığı toplamının sabit ve sonik kristal genişliğine $\left(, d=d_{o}+D_{1}\right)$ eşit olduğu gömrülmüştür. Simülasyon sonuçları Eşitlik 1 ile ifade edilmiş olan 1şın izleme ile yapılan analizlere uygun sonuçlar vermiştir. Diğer bir önemli nokta ise kaynak yerinin değişme miktarı kadar $\Delta D_{1}$, odak uzaklığında değişim $\Delta d_{0}=-\Delta D_{1}$ olmasıdır. Bu özellikler, düzlem akustik lens kullanarak ses kaynağının konumunun hassas bir şekilde odak uzaklığı konumunu ile belirlenmesine imkân sağlayabilir. Ayrıca kaynak konumu ayarlanarak akustik dalga enerjisinin sonik kristal düzlemin diğer tarafında odakladığı noktanın ayarlanabilmesinin mümkün olduğu görülmüştür.

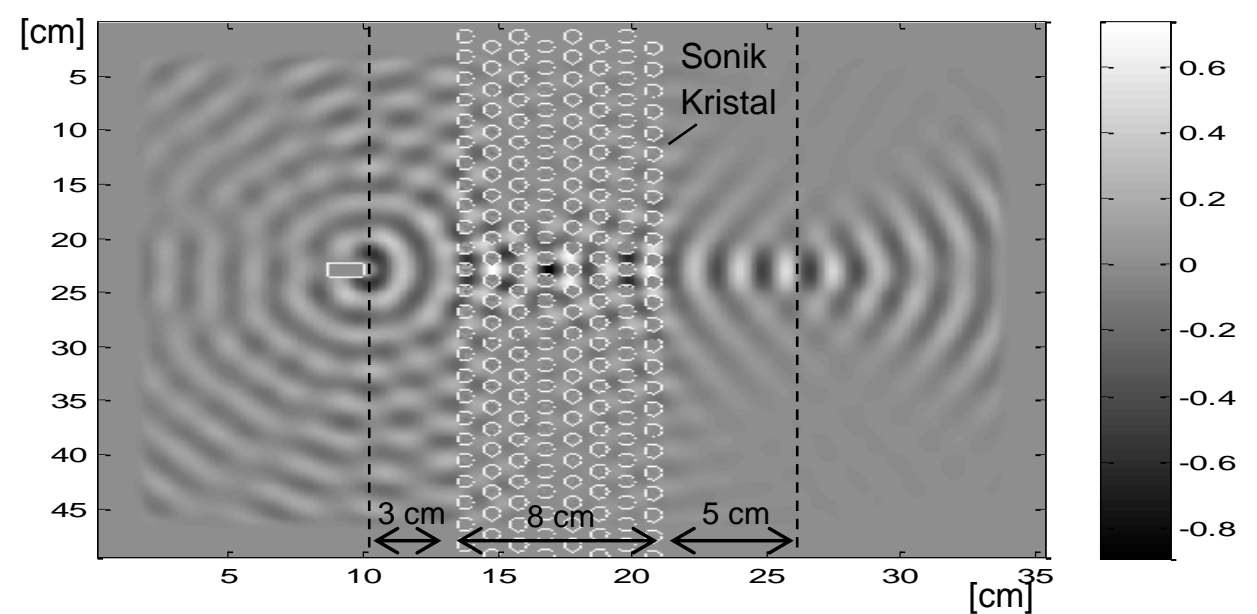

Şekil $9 n \cong-1$ durumunda, akustik kaynak noktası sonik kristalden $3 \mathrm{~cm}$ uzakta ve odak noktası 5 cm'de oluştu. (Kristal yapıya olan uzaklıklarının toplamları, sonik kristal kalınlığı olan $8 \mathrm{~cm}$ 'dir) 


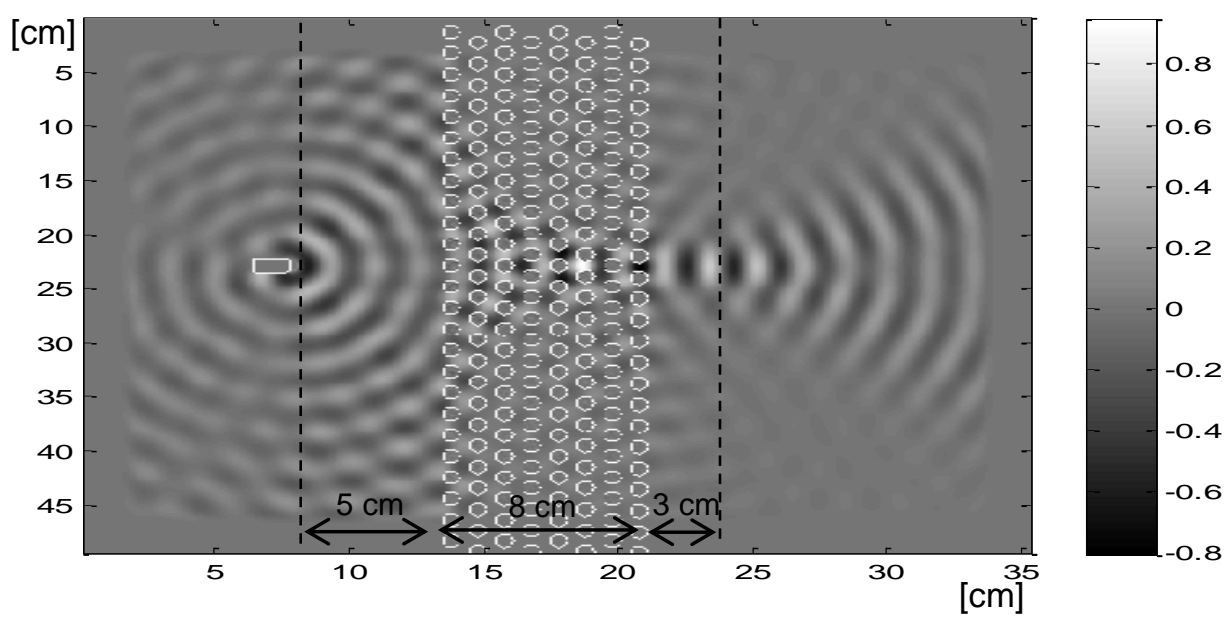

Şekil $10 n \cong-1$ durumunda, akustik kaynak noktası sonik kristalden $5 \mathrm{~cm}$ uzakta ve odak noktası 3 cm'de oluştu (Kristal yapıya olan uzaklıklarının toplamları, sonik kristal kalınlığı olan 8 cm'dir)

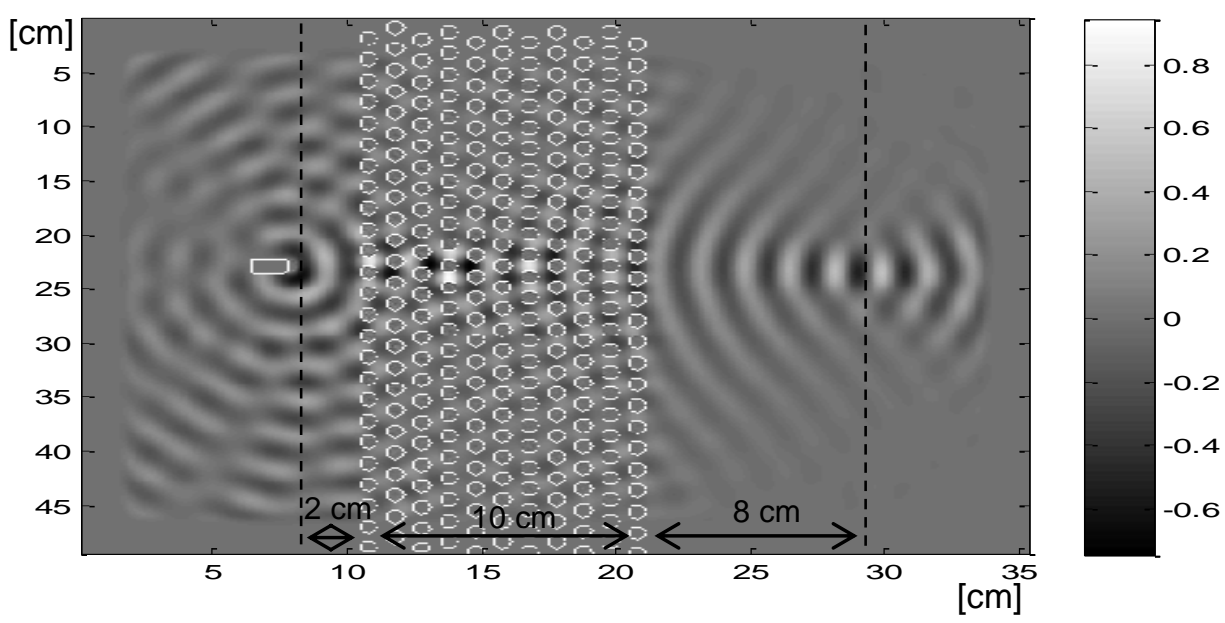

Şekil $11 n \cong-1$ durumunda, sonik kristal kalınlığ $10 \mathrm{~cm}$ olduğunda akustik kaynak uzaklığ $2 \mathrm{~cm}$ ve odak uzaklığı $8 \mathrm{~cm}$ 'de oluştu (Kristal yapıya olan uzaklıklarının toplamları, sonik kristal kalınlığı olan $10 \mathrm{~cm}$ 'dir)

Negatif kırınıma sahip sonik kristal düzlem lensler ile dalga boyu altında ayırıcılığa (çözünürlüğe) sahip odaklama sağlayabilmektedir. Bu özellik akustik görüntülemede sonik kristal düzlem lensler yardımı ile çözünürlüğün artırılmasını sağlayabilir. Bu özelliği, zaman bölgesi sonlu farklar simülasyonlarında iki noktasal kaynağın birbirine yakınlaştırılması ve odak noktalarının birbirinden ayırılabilirliği ile incelenebilir. Noktasal kaynaklar arasındaki mesafe dalga boyu $\lambda$ 'nın altına düştüğü zaman noktasal kaynakların odak noktalarının birbirinden ayrılabilmesi dalga boyu altı çözünürlügün geçerliliğine işaret eder. Şekil 12'de dalga boyu altında ayırıcılı̆̆ı incelemek için noktasal iki kaynak arasındaki mesafenin sırası ile $0.47 \lambda$ (Şekil 12 a,b), $0.80 \lambda$ (Şekil 12 c,d), 1.00 $\lambda$ (Şekil $12 \mathrm{e}, \mathrm{f}$ ) ve $1.57 \lambda$ (Şekil $12 \mathrm{~g}, \mathrm{~h}$ ) için similasyon sonuçları sunulmuştur. Burada, $\lambda$ kaynaklardan yayılan dalganın dalga boyunu ifade etmektedir. Kaynaklar arası mesafenin $0.47 \lambda$ olduğu durumda odak noktalarının birbirinden ayrılması mümkün olmamıştır. Ancak, kaynaklar arası mesafenin $0.80 \lambda$ 'ya çıkarıldığı durumda odak noktalarının birbirinden ayrılması mümkün olmuş ve böylece dalga boyu altı çözünürlük özelliği simülasyon yardımı ile gözlemlenebilmiştir. 

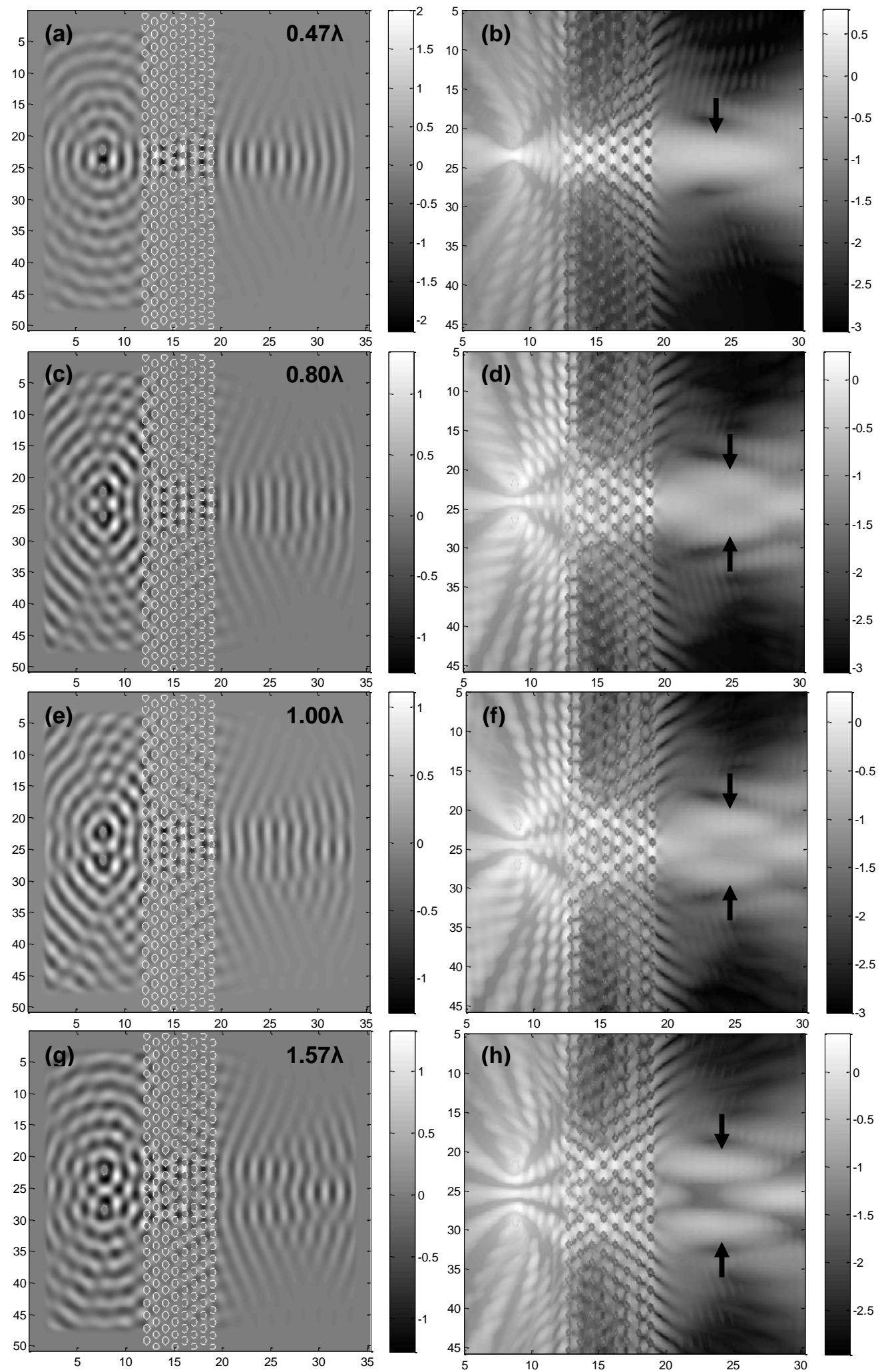

3 Şekil 12. İki kaynaklı sistemde kaynaklar arasındaki mesafe $0.47 \lambda, 0.80 \lambda, 1.00 \lambda$ ve $1.57 \lambda$ için 4 simülasyon sonuçları ve odak noktaları

Bu çalışmada sonik kristallerde negatif kırınım özelliği ve bu özelliğe bağlı olarak sonik kristal 8 düzlem lens özellikleri, zaman bölgesi sonlu farklar simülasyon sonuçları yardımı ile incelenmiştir. Bu 
lenslere ait kaynak konumuna bağlı odak noktası konumu $\left(d_{o}=d-D_{1}\right)$ ve dalga boyu altı çözünürlük özelliklerinin zaman bölgesi sonlu farklar simülasyonları ile bir incelesi sunulmuştur. Böylece, zaman bölgesi sonlu farklar simülasyonları yardımı ile bu özellikleri kullanabilen uygulamalar ve akustik lens tasarımlarının geliştirilebileceği görülmüştür. Bu özellikler yardımı ile sonik ve akustik görüntüleme sistemlerinin iyileştirilmesine dönük simülasyon çalışmalarının yapılabileceği sonucuna varılmıştır. Simülasyon sonuçlarında $n \cong-1$ durumunda odak uzaklığının $d_{o}=d-D_{1}$ uygun değişiminin, düzlem akustik lens yardımı ile iki uygulamaya imkân sağlayabileceği görülmüştür. Birincisi, akustik ses kaynağının konumunun, düzlem lens'den geçen dalganın odaklanma uzaklığına göre belirlenebilmesi ile yakın-alan akustik kaynak konum tespiti uygulamalarına imkân sağlayabilir. Diğeri, kaynak konumu ayarlanması ile akustik dalga enerjisinin sonik kristal düzlemin diğer tarafında odaklandığ noktanın ayarlanabilmesi imkânı, akustik enerji odaklama uygulamalarına katkı sağlayabilir.

\section{KAYNAKLAR}

Alagoz BB, Alagoz S, 2011. Towards earthquake shields: A numerical investigation of earthquake shielding with seismic crystals. Open Journal of Acoustics 1(3): 63-69.

Alagoz S, Kaya OA, Alagoz BB, 2009. Frequency-controlled wave focusing by a sonic crystal lens. Applied Acoustics 70(11): 1400-1405.

Alagoz S. (2011). Experimental observation of far-field and near-field focusing in a sonic crystal flat lens in air. Measurement Science and Technology 22(11): 115105.

Alagoz S, (2012). An Investigation on Acoustic Wave Focalization by a Square Lattice Flat Lens. Archives of Acoustics, 37, 81-87.

Chao-Hsien K, Zhen Y, 2004. Crystal lenses that obey the lensmaker's formula. J. Phys. D: Appl. Phys. 37: 2155-2159

Cervera F, Sanchis L, Sanchez-Perez JV, Martinez-Sala R, Rubio C, Meseguer F, Lopez C, Caballero D, Sanchez-Dehesa J, 2001. Refractive Acoustic Devices for Airborne Sound. Phys. Rev. Lett. 88: 023902.

Climente A, Torrent D, Sánchez-Dehesa J (2010). Sound focusing by gradient index sonic lenses. Applied Physics Letters, 97(10): 104103.

Feng L, Liu XP, Chen YB, Huang ZP, Mao YW, Chen YF, Zi J, Zhu YY, 2005. Negative refraction of acoustic waves in two-dimensional sonic crystals. Phys. Rev. B 72:033108.

Foteinopoulou S, Economou EN, Soukoulis CM 2003. Refraction at media with negative refractive index. Phys. Rev. Lett. 90:107402.

Houck AA, Brock JB, Chuang IL, 2003. Experimental observations of a left-handed material that obeys snell's law. Phys. Rev. Lett. 90:137401.

Jia W, Zhang S 2007. Strongly frequency-dependent negative refraction of a two-dimensional sonic crystal wedge. Physics Letters A 372:721-724.

Liu A, Zhou X, Huang G, Hu G, 2012. Super-resolution imaging by resonant tunneling in anisotropic acoustic metamaterials. The Journal of the Acoustical Society of America, 132(4):2800-2806.

Liu T, Chen F, Liang S, Gao H, Zhu J, 2019. Subwavelength sound focusing and imaging via gradient metasurface-enabled spoof surface acoustic wave modulation. Physical Review Applied, 11(3): 034061 . 
Miyashita T, Inoue C, 2001. Numerical investigations of transmission and waveguide properties of sonic crystals by finite-difference time-domain method. Japan. J. Appl. Phys. 40:3488-92.

3 Miyashita T, 2005. Sonic crystals and sonic wave-guides”, Meas. Sci. Technol.16:R47-R6.

4 Hirsekorn M, 2006. Elastic Wave Propagation in Locally Resonant Sonic Materials. Thesis for the Degree of Ph. D. of The University of Politecnico Di Torino, Italy.

Martinez-Sala R, Sancho J, Sanchez JV, Gomez V, Llinares J, Meseguer F,1995. Sound attenuation by sculpture. Nature 378:241.

Miniaci M., Krushynska, A., Bosia, F., \& Pugno, N. M. (2016). Large scale mechanical metamaterials as seismic shields. New Journal of Physics, 18(8), 083041.

Mu D., Shu, H., Zhao, L., \& An, S. (2020). A review of research on seismic metamaterials. Advanced Engineering Materials, 22(4), 1901148.

Ozbay E, Aydin K, Bulu I, Guven K, 2007. Negative refraction, subwavelength focusing and beam formation by photonic crystals, J. Phys. D: Appl. Phys. 40, 2652-2658.

Qiu C, Zhang X, Liu Z, 2005.Far-field imaging of acoustic waves by a two-dimensional sonic crystal. Phys Reviev B 2005; 71: 054302.

Pendry JB, 2000. Negative refraction makes a perfect lens. Phys. Rev. Lett. 85(18): 3966-3969.

Sigalas MM, Garcia N, 2000. Theoretical study of three dimensional elastic band gaps with the finitedifference time-domain methods, J. Appl. Phys. 87, 3122-5.

Veselago VG, 1968. The electrodynamics of substances with simultaneously negative values of permittivity and permeability. Sov. Phys. Upekhi 10 (4):509-514.

Wang J, 2020. A seismic-shielding structure based on phononic crystal. Revista de la Construcción. Journal of Construction, 19(3): 272-287.

Zhang XD, Liu ZY, 2004. Negative refraction of acoustic waves in two-dimensional phononic crystals. Appl. Phys. Lett. 85: 341.

Zhu J Christensen J, Jung J, Martin-Moreno L, Yin X, Fok L, Garcia-Vidal FJ, 2011. A holey-structured metamaterial for acoustic deep-subwavelength imaging. Nature physics 7(1):52-55. 